\title{
Minireview
}

\section{When Morphology Meets Somatic Mutations: The New Possible Scenario in Thyroid Fine-Needle Aspiration}

\author{
Esther Diana Rossi ${ }^{\mathrm{a}} \quad$ Fernando Schmitt ${ }^{\mathrm{b}-\mathrm{d}}$ \\ ${ }^{a}$ Division of Anatomic Pathology and Histology, Agostino Gemelli School of Medicine, Università Cattolica del \\ Sacro Cuore, Rome Italy; ${ }^{\mathrm{b}}$ Instituto de Patologia e Imunologia Molecular da Universidade do Porto (IPATIMUP) and \\ 'Medical Faculty, University of Porto, Porto, Portugal; ' Department of Medicine, Laboratoire National de Santé, \\ Dudelange, Luxembourg
}

\section{Key Words}

BRAF mutation · Liquid-based cytology · Malignancies .

Plump cells · Thyroid fine-needle aspiration

\begin{abstract}
This study points to the analysis of the morphological features suggestive of somatic mutations, mostly the $B R A F^{V 600 E}$ mutation, on cytological samples of thyroid carcinomas. According to the literature, the application of ancillary techniques on cytology comes in handy as a challenging aid in ruling out a malignant outcome on both conventional and liquid-based cytological preparations. However, the evaluation of somatic mutations, including $B R A F^{V 600 E}$, usually performed by DNA techniques, may have some limitations in a worldwide diffusion. In this perspective, few authors emphasized the morphological search for BRAF ${ }^{V 600 E}$ mutations harbored in papillary thyroid carcinoma (PTC) and characterized by specific architectural and cellular findings (i.e. eosinophilic cells defined as 'plump cells' and sickle-shaped nuclei). Hence, the detection of eosinophilic cytoplasm of mutated PTC cells seems to suggest the possible involvement of the 'Warburg effect' pioneering the ability of cancer cells to convert glucose into lactic acid. The recent yields of immunohistochemical expression of monocarboxylate transporters in
\end{abstract}

mutated PTCs may suggest the accumulation of lactate in these plump cells. Equally importantly, the detection of these morphological findings using fine-needle aspiration cytology may be helpful in triaging thyroid lesions and limiting costs. Additionally, it may lead to the stratification of the malignant risk and personalized management in cases with multifocal lesions.

(c) 2016 S. Karger AG, Basel

The worldwide acceptance that somatic mutations represent a hallmark in the diagnosis and prognosis of cancer has been widely established [1-5]. Remarkable advances in the knowledge of the molecular mechanisms of cancer have been done in these last decades mostly due to the application of molecular platforms and next-generation sequencing able to identify the driver mutations of numerous different cancers [1-7]. Specifically, several scientific data have shown that molecular alterations in specific pathways play a pivotal role in different types of thyroid cancer and, equally importantly, arise early in the tumorigenic process so that they may be considered as strong markers of malignancy [1-11]. Especially papillary thyroid carcinoma (PTC), the most common thyroid malignancy, may carry BRAF, RET/PTC or N-RAS muta-

\section{KARGER}

E-Mail karger@karger.com www.karger.com/acy
C 2016 S. Karger AG, Basel

0001-5547/16/0602-0093\$39.50/0
Correspondence to: Dr. Esther Diana Rossi

Division of Anatomic Pathology and Histology, Agostino Gemelli School of Medicine Università Cattolica del Sacro Cuore

Largo Francesco Vito 1, IT-00168 Rome (Italy)

E-Mail esther.rossi@rm.unicatt.it 
tions [12]. Among them, activating somatic mutations in the $B R A F$ oncogene proved high prevalence (ranging between 45 and 70\%) mainly in the classical variant of PTCs with more than $95 \%$ of $B R A F$ mutations involving the hot spot identified on exon 15 of the $\mathrm{B}$ isoform of the $R A F$ kinase gene [13].

\section{Some Changes in The Molecular Approach}

Although these innovative molecular approaches represent the gold standard for DNA and RNA evaluations, they do not fulfill a worldwide diffusion and application. In fact, their invaluable advantages are countered by several issues, including more laborious investigations, timeconsuming, more expensive equipment, necessity of dedicated technical personnel or contamination by nonneoplastic components, which lead to an unpredictable rate of nondiagnostic molecular yields $[14,15]$. Taking all these limitations into account, some authors cudgeled their brains in order to find some efficient and possible alternatives for a reliable detection of somatic mutations [15-21]. To overcome these drawbacks, some of them fostered the study and evaluation of antibodies against the mutated proteins as well as the possible identification of specific morphological features able to recognize mutated thyroid carcinomas.

\section{The Role of VE1 Antibody}

However, did these alternative approaches reach their goal? In 2012, Capper et al. [16] suggested that a new monoclonal antibody directed against the mutated $B R A F$ V600E protein (clone VE1) was likely to be promoted as a valid option in several malignant neoplasms. Comparing the immunohistochemical yields with molecular assays, these authors showed that VE1 also had high sensitivity and specificity in a series including 47 melanoma metastases and 21 papillary thyroid carcinomas [16]. In a second paper, they yielded $97 \%$ correlation between VE1 and molecular BRAF with only 2 discordant cases [15]. Hence, Routhier et al. [19] found also high concordance between VE1 and molecular assays (97\%) in a series of 152 malignant tumors including also 23 thyroid carcinomas. The application of VE1 on cytological samples resulted in $86 \%$ sensitivity and specificity as found in two different papers from Zimmerman et al. [21] and Rossi et al. [14]. Nevertheless, some criticism and controversial data have been raised mostly due to the weak and focal positivity expressed in some thyroid lesions.

In fact, despite the fact that the literature exploited VE1 antibody as a feasible first-line approach for the evaluating BRAF mutations, Rossi et al. [14] highlighted that it was less accurate in identifying VE1-negative cases than molecular platforms.

\section{The New Perspective of Morphological Findings of Mutation}

Is there anything else helpful to predict mutations based on thyroid fine-needle aspiration cytology (FNAC)? The idea of the possible prediction of the mutational status of cancer cells was an alternative perspective suggested by recent papers on thyroid histological PTCs. Specifically, in 2012, Finkelstein et al. [22] proved that distinctive morphological features were harbored in histological samples of $B R A F^{V 600 E}$-mutated PTCs. Taking these data into account, the same results were pointed out by Virk et al. [23] in 2014 showing that some architectural (tumor-associated stromal reactions or infiltrative tumor borders) and cellular-specific parameters (nuclear features and polygonal eosinophils defined as 'plump cells') are linked with $B R A F^{V 600 E}$-mutated PTC. Simple fluke? Or may we exploit 'mutational eyes'?

These recent papers shed light on the exciting, potential opportunity to implement the same search on thyroid cytology in order to offer a valid tool in selecting cases for molecular analysis and limiting costs. Consequently, the awareness of these histological findings has raised our interest in their evaluation in our cytological series of thyroid lesions diagnosed as positive for malignancy favoring PTC. Rossi et al. [24, 25] identified peculiar morphological features in all the 47 mutated cases, including also $6 B R A F^{V 600 E}$-mutated cases with focal 'plump cells'. Hence, an accurate morphological investigation suggested also the recognition of a peculiar nuclear shape in all the $B R A F^{V 600 E}$ cases which had not been previously described in literature. In fact, these authors demonstrated the presence of mutated cancer cells characterized by nuclei which tended to be smaller, pleomorphic and eccentrically located with a particular sickle shape, which was absent in wild-type cases $[24,25]$. However, the presence of these plump cells with sickleshaped nuclei has recently been confirmed by Kwon et al. [26] in a series of 142 thyroid lesions diagnosed as suspicious for malignancy and performed with conventional cytology.
Rossi/Schmitt 
Moreover, a recent study of ours (data under publication) assessed the detection of morphological parameters associated with the $B R A F^{V 600 E}$ mutation in a series of 119 pediatric cytological lesions emphasizing that they may be easily recognized regardless of the thyroid category and helped in guiding the correct management in pediatric thyroid lesions.

Nevertheless, these findings have recently also been documented in other $B R A F^{V 600 E}$-mutated cancers [27, 28]. For example, the morphological features of $B R A F^{V 600 E}$ mutations were underscored in a recent study even in ovarian neoplastic lesions. Consistently, in 2014, Zeppernick et al. [27] described some morphological features that may predict $B R A F^{V 600 E}$ mutations in ovarian serous borderline tumors which are highly likely to induce neoplastic initiation followed by a mechanism to restrain tumor progression and reach a low-stage senescent disease. Given that, are these new insights regarding thyroid and ovarian $B R A F^{V 600 E}$ neoplasms driven and supported by the same metabolic mechanism?

How are $B R A F^{V 600 E}$ and morphology linked? In this perspective, we emphasized that a $B R A F^{V 600 E}$-activating mutation is likely to exert a different effect on the nucleus/cytoplasm ratio in favor of abundant cytoplasm in mutated cases.

\section{The Molecular Mechanism}

In this regard, the detection of the abundant eosinophilic cytoplasm of mutated thyroid cancer cells seems to stand a chance of involving the 'Warburg effect' inducing a modified metabolism of cancer cells able to convert glucose into lactic acid due to the up-regulation of genes involved in glycolysis [29-31]. As recently published, it has been proven that the metabolic use of glucose in glycolysis, with production of ketones, promotes the $B R A F^{V 600 E_{-}}$ MEK.ERK oncogenic pathway [32]. Taking into account the glycolytic mechanisms beneath, these $B R A F^{V 600 E}$-mutated cells may hesitate in an increased mitochondrial respiration justifying the abundant and eosinophilic cytoplasm of the cells through both MEK/ERK activation and mitochondrial translocation with an anti-apoptotic effect $[31,33]$. The anti-apoptotic effect and the enhanced glycophenotypes may be the final effect of the localization within the outer mitochondrial membrane inducing the cleavage effect of inhibition of the caspase pathway and lack of resistance to intrinsic and extrinsic apoptotic stimuli [31].

However, are we able to target this suggestion in our everyday practice even on FNAC?

\section{The Expression of MCTs}

Thus, the altered metabolic profile and the hypothetical glycolytic metabolisms seem to be supported by the immunocytochemical analysis of the monocarboxylate transporter (MCT) family which may give rise to the accumulation of lactate in these thyroid mutated cancer cells [34-37]. However, the exact and specific role of MCTs in thyroid $B R A F^{V 600 E}$-mutated carcinomas is still far from being fully characterized and thus their role as an additional therapeutic target can still not be translated into the clinical context [34-37]. Our preliminary data (not yet published) showed that the expression of both MCT1 and MCT4 in plump mutated thyroid cancers is likely to justify that lactate can be involved in these morphological features. In fact, MCT1 yielded $76 \%$ positivity in the mutated cases, especially in both plump cells and sickle-shaped nuclei, whereas MCT4 resulted in $100 \%$ positivity in mutated cases.

In conclusion, these morphological features may be a reliable foreseeable parameter of $B R A F^{V 600 E}$ mutations especially in mutated PTCs suggesting plausible additional oncogenic BRAF mechanisms. Their morphological detection in cytological samples may lead to a selection of cases for molecular BRAF analysis limiting costs especially in cases of multifocal cancers. Hence, their recognition may predict a malignant cytological diagnosis regardless of the cytological diagnostic categorization. Furthermore, investigating the genetic underpinnings of the detection of plump cells and sickle-shaped nuclei may pave the way for obtaining an accurate knowledge of the molecular mechanism of other different oncogenic drivers so that this knowledge may lead to the organ-specific triaging of cases in order to provide important insight for future tailored targeted therapies.

\section{Disclosure Statement}

None of the authors listed above has a potential conflict of interest. None of the authors received any funding sources for the paper.

References

$>_{1}$ Jung CK, Little MP, Lubin JH, Brenner AV, Wells SA Jr, Sigurdson AJ, Nikiforov YE: The increase in thyroid cancer incidence during the last four decades is accompanied by a high frequency of BRAF mutations and a sharp increase in $R A S$ mutations. J Clin Endocrinol Metab 2014;10:2503-2513.

-2 Nikiforova MN, Nikiforov Y: Molecular diagnostics and predictors in thyroid cancer. Thyroid 2009; 19:1351-1361.

-3 Nikiforov YE: Molecular diagnostics of thyroid tumors. Arch Pathol Lab Med 2011;135: 569-577. 
4 McCarthy N: Metabolism: mutant BRAF feels the burn. Nat Rev Cancer 2015;15:454-455.

5 White E: Exploiting the bad eating habits of Ras-driven cancers. Genes Dev 2015;27: 2065-2071.

6 Nikiforov Y, Carty SE, Chiosea SI, Coyne C, Duvvuri U, Ferris RL, Gooding WE, Hodak SP, LeBeau SO, Ohori NP, Seethala RR, Tublin ME, Yip L, Nikiforova MN: Highly accurate diagnosis of cancer in thyroid nodules with follicular neoplasm/suspicious for a follicular neoplasm cytology by ThyroSeq v2 next-generation sequencing assay. Cancer 2014;120:3627-3634.

-7 Nikiforova M, Wald Al, Roy S, Durso MB, Nikiforov Y: Targeted next-generation sequencing (ThyroSeq) for detection of mutations in thyroid cancer. J Clin Endocrinol Metab 2013; 98:E1852-E1860.

8 Mathur A, Moses W, Rahbari Khanafshar E, Duh QY, Clark O, Kebebew E: Higher rate of $B R A F$ mutation in papillary thyroid cancer over time: a single-institution study. Cancer 2011;117:4390-4395.

9 Xing M: BRAF mutation in papillary thyroid cancer: pathogenic role, molecular bases and clinical implications. Endocr Rev 2007;28: 742-762.

10 Kim TH, Park YJ, Lim JA, Ahn HY, Lee EK, Lee YJ, Kim KW, Hahn SK, Youn YK, Kim $\mathrm{KH}$, Cho BY, Park do J: The association of the $B R A F^{\mathrm{V} 600 \mathrm{E}}$ mutation with prognostic factors and poor clinical outcome in papillary thyroid cancer: a meta-analysis. Cancer 2012;118 1764-1773.

11 Guerra A, Fugazzola L, Marotta V, Cirillo M, Rossi S, Cirello V, Forno I, Moccia T, Budillon A, Vitale M: A high percentage of $B R A F^{V 600 E}$ alleles in papillary thyroid carcinoma predicts a poorer outcome. J Clin Endocrinol Metab 2012;97:2333-2340.

12 Gandolfi G, Sancisi V, Piana S, Ciarrocchi A: Time to re-consider the meaning of $B R A F$ V600E mutation in papillary thyroid carcinoma. Int J Cancer 2015;137:1001-1011.

13 Rossi ED, Martini M, Capodimonti S, Lombardi CP, Pontecorvi A, Vellone VG, Zannoni GF, Larocca LM, Fadda G: BRAF (V600E) mutation analysis on liquid-based cytologyprocessed aspiration biopsies predicts bilaterality and lymph node involvement in papillary thyroid microcarcinoma. Cancer Cytopathol 2013;121:291-297.

14 Rossi ED, Martini M, Capodimonti S, Cenci T, Straccia P, Angrisani B, Ricci C, Lanza P, Lombardi CP, Pontecorvi A, Larocca LM, Fadda G: Analysis of immunocytochemical and molecular BRAF expression in thyroid carcinomas: a cytohistologic institutional experience. Cancer Cytopathol 2014;122:527535.

-15 Capper D, Preusser M, Habel A, Sahm F, Ackermann U, Schindler G, Pusch S, Mechtersheimer $\mathrm{G}$, Zentgraf $\mathrm{H}$, von Deimling A: Assessment of BRAF V600E mutation status by immunohistochemistry with a mutationspecific monoclonal antibody. Acta Neuropathol 2011;122:11-19.

-16 Capper D, Berghoff AS, Magerle M, Ilhan A, Wöhrer A, Hackl M, Pichler J, Pusch S, Mey- er J, Habel A, Petzelbauer P, Birner P, von Deimling A, Preusser M: Immunohistochemical testing of BRAF V600E in 1,120 tumor tissue samples of patients with brain metastases. Acta Neuropathol 2012;123:223233.

Long GV, Wilmott JS, Capper D, Preusser M, Zhang YE, Thompson JF, Kefford RF, von Deimling A, Scolyer RA: Immunohistochemistry is highly sensitive and specific for the detection of V600E BRAF mutation in melanoma. Am J Surg Pathol 2013;37:61-65.

18 Ghossein RA, Katabi N, Fagin JA: Immunohistochemical detection of mutated BRAF V600E supports the clonal origin of BRAFinduced thyroid cancers along the spectrum of disease progression. J Clin Endocrinol Metab 2013;98:E1414-E1421.

19 Routhier CA, Mochel MC, Lynch K, DiasSantagata D, Louis DN, Hoang MP: Comparison of 2 monoclonal antibodies for immunohistochemical detection of BRAF V600E mutation in malignant melanoma, pulmonary carcinoma, gastrointestinal carcinoma, thyroid carcinoma and gliomas. Hum Pathol 2013;44:2563-2570.

20 Koperek O, Kornauth C, Capper D, Berghoff AS, Asari R, Niederle B, von Deimling A, Birner P, Preusser M: Immunohistochemical detection of the BRAF V600E-mutated protein in papillary thyroid carcinoma. Am J Surg Pathol 2012;36:844-850.

21 Zimmermann AK, Camerisch U, Rechsteiner MP, Bode-Lesniewska B, Rossle M: Value of immunohistochemistry in detection of BRAF $\mathrm{V} 600 \mathrm{E}$ mutations in fine needle aspiration biopsies of papillary thyroid carcinoma. Cancer Cytopathol 2014;122:48-58.

22 Finkelstein A, Levy GH, Hui P, Prasad A, Virk R, Chhieng DC, Carling T, Roman SA, Sosa JA, Udelsman R, Theoharis CG, Prasad ML: Papillary thyroid carcinomas with and without BRAF V600E mutations are morphologically distinct. Histopathology 2012;60:1052-1059.

23 Virk RK, Theoharis CGA, Prasad A, Chhieng D, Prasad ML: Morphology predicts $B R A F^{V 600 E}$ mutation in papillary thyroid carcinoma: an interobserver reproducibility study. Virchows Arch 2014;464:435-442.

24 Rossi ED, Bizzarro T, Martini M, Capodimonti S, Fadda G, Larocca LM, Schmitt F: Morphological parameters able to predict $B R A F^{V 600 E}$-mutated malignancies on thyroid fine-needle aspiration cytology: our institutional experience. Cancer Cytopathol 2014; 122:883-891.

25 Rossi ED, Bizzarro T, Fadda G, Larocca LM, Schmitt F: Is morphology alone able to predict $B R A F$-mutated malignancies on thyroid FNAC? Virchows Arch 2014;465:247-248.

26 Kwon H, Kim EK, Kwak JY: Cytomorphologic features in thyroid nodules read as 'suspicious for malignancy' on cytology may predict thyroid cancer with the BRAF mutation. Pathol Res Pract 2015;211:671-676.

-27 Zeppernick F, Ardighieri L, Hannibal CG, Vang R, Junge J, Kjaer SK, Zhang R, Kurman RJ, Shih IeM: $B R A F$ mutation is associated with a specific cell type with features sugges- tive of senescence in ovarian serous borderline (atypical proliferative) tumors. Am J Surg Pathol 2014;38:1603-1611.

28 Ardighieri L, Zeppernick F, Hannibal CG, Vang R, Cope L, Junge J, Kjaer SK, Kurman RJ, Shih IeM: Mutational analysis of $B R A F$ and KRAS in ovarian atypical proliferative serous (borderline) tumors and associated peritoneal implants. J Pathol 2014;232:1994-2000.

29 Arozarena I, Sanchez-Laorden B, Packer L, Hidalgo-Carcedo C, Hayward R, Viros A, Sahai E, Marais R: Oncogenic BRAF induces melanoma cell invasion by downregulating the cGMP-specific phosphodiesterase PDE5A. Cancer Cell 2011;19:45-57.

30 Hall A, Meyle KD, Lange MK, Klima M, Sanderhoff M, Dahl C, Abildgaard C, Thorup K, Moghimi SM, Jensen PB, Bartek J, Guldberg P, Christensen C: Dysfunctional oxidative phosphorylation makes malignant melanoma cells addicted to glycolysis driven by the ${ }^{V 600 E-}$ $B R A F$ oncogene. Oncotarget 2013;4:584-599.

31 Lee MH, Lee SE, Kim DW, Ryu MJ, Kim SJ, Kim SJ, Kim YK, Park JH, Kweon GR, Kim JM, Lee JU, De Falco V, Jo YS, Shong M: Mitochondrial localization and regulation of $B R A F^{V 600 E}$ in thyroid cancer: a clinically used RAF inhibitor is unable to block the mitochondrial activities of $B R A F^{V 600 E}$. J Clin Endocrinol Metab 2011;96:E19-E30.

- 32 Kang HB, Fan J, Lin R, Ji Q, Zhao L, Jin L, Seo JH, Shan C, Arbiser JL, Cohen C, Brat D, Miziorko HM, Kim E, Abdel-Wahab O, Merghoub T, Fröhling S, Scholl C, Tamayo P, Barbie DA, Zhou L, Pollack BP, Fisher K, Kudchadkar RR, Lawson DH, Sica G, Rossi M, Lonial S, Khoury HJ, Khuri FR, Lee BH, Boggon TJ, He C, Kang S, Chen J: Metabolic rewiring by oncogenic BRAF V600E links ketogenesis pathway to BRAF-MEK1 signaling. Mol Cell 2015;59:345-358..

33 Viale A, Corti D, Draetta GF: Tumors and mitochondrial respiration: a neglected connection. Cancer Res 2015;75:3687-3691.

34 Pinheiro C, Penna V, Morais-Santos F, Abrahao-Machado LF, Ribeiro G, Curcelli EC, Olivieri MV, Morini S, Velnca I, Ribeiro D, Schmitt F, Reis RM, Baltazar F: Characterization of monocarboxylate transporters (MCTs) expression in soft tissue sarcomas: distinct prognostic impact of MCT1 subcellular localization. J Transl Med 2014;12:118-128.

35 Pinheiro C, Longatto-Filho A, Scapulatempo C, Ferreira L, Martins S, Pellerin L, Rodrigues M, Alves VAF, Schmitt F, Baltazar F: Increased expression of monocarboxylate transporters 1, 2 and 4 in colorectal carcinomas. Virchows Arch 2008;452:139-146.

36 Pinheiro C, Albergaria A, Paredes J, Sousa B, Dufloth R, Vieira D, Schmitt F, Baltazar F: Monocarboxylate transporter 1 is up-regulated in basal-like breast carcinoma. Histopathology 2010;56:860-867.

37 Pinheiro C, Longatto-Filho A, Soares T, Pereira H, Bedrossian C, Michael C, Schmitt FC, Baltazar F: CD147 immunohistochemistry discriminates between reactive mesothelial cells and malignant mesothelioma. Diagn Cytopathol 2012;40:478-483. 